\title{
Life Cycle Assessment in Municipal Solid Waste Management
}

\author{
Konstadinos Abeliotis \\ Harokopio University \\ Greece
}

\section{Introduction}

Integrated Municipal Solid Waste (MSW) management is a tedious task requiring the simultaneous fulfilment of technical, economical and social constraints. It combines a range of collection and treatment methods to handle all materials in the waste stream in an environmentally effective, economically affordable and socially acceptable way (McDougall, 2001). Due to the complexity of the issues required for effective integrated MSW management, various computer-aided approaches that help the decision makers reach their final decision have been engaged since the early days of integrated MSW management. Any computer-based system supporting decision making is defined as a DSS (Finlay, 1989). DSS incorporate computer-based models of real life biophysical and economic systems. There are two main categories of DSS applied to solid waste management: the first one, based on applied mathematics, emphasises application of statistical, optimisation or simulation modelling. The second category of DSS provides specific problem-solving expertise stored as facts, rules and procedures. In addition, there are also hybrid approaches.

Recently, there has been a major shift towards Life Cycle Assessment (LCA) computer-aided tools. LCA is a holistic approach that is increasingly utilised for solid waste management especially in the decision-making process and in strategy-planning. LCA can be categorised as a hybrid approach since it utilises equations for inventory analysis and recycling loops on the one hand, while on the other it requires expertise input for impact assessment and characterisation.

Life Cycle Assessment (LCA) is a holistic approach that quantifies all environmental burdens and therefore all environmental impacts throughout the life cycle of products or processes (Rebitzer et al. 2004). LCA is not an exact scientific tool, but a science-based assessment methodology for the impacts of a product or system on the environment (Winkler \& Bilitewski 2007). It is increasingly utilised for solid waste management systems especially in the decision-making process and in strategy-planning. LCA has been utilised for sustainable MSW management since 1995 (Güereca et al. 2006). LCA is an ideal tool for application in MSW management because geographic locations, characteristics of waste, energy sources, availability of some disposal options and size of markets for products derived from waste management differ widely (White et al., 1997; Mendes et al., 2004). LCA can help reduce local pressures and waste management costs, while considering the broader effects and trade-offs felt elsewhere across society (Koneczny and Pennington, 2007).

The LCA procedure has been standardized in 1998 and revised in 2006 (ISO 14040, 2006). Based on this standard, LCA consists of the following four sections: 
- Goal and scope definition,

- $\quad$ Life cycle inventory (LCI),

- Life cycle impact assessment (LCIA),

- Life cycle interpretation.

\section{Objective of the chapter}

The objective of this chapter is the critical presentation of recent peer-reviewed research articles dealing with various stages of MSW management using the LCA methodology. In each article the main LCA components are presented (Goal and scope, functional unit, main assumptions, data sources for the compilation of the LCI, LCIA categories) in addition to the main conclusions of the study. Based on this review, conclusions are drawn for answering the key chapter question "What have we learned from the application of LCA to MSW?"

\section{The challenge of dealing with the life cycle of MSW management}

The application of LCA in MSW management is a very challenging task due to the following reasons:

- Every single waste management facility is considered a priori as environmentally friendly. However, solid waste management facilities require land (a lot of land in the case of landfills), consume non renewable natural resources for their operation (e.g. fuels and electricity) and emit a series of air pollutants and leachates. Therefore, waste management facilities put an environmental burden of their own on the natural environment. The trade-offs between environmental gains and burdens have to be assessed.

- Solid waste management facilities on the other hand generate a lot of useful "products"; Material reclamation facilities produce different sorts of paper and cardboard, glass, plastics, etc. A mechanical biological treatment facility generates RDF, which can be used as a solid fuel in cement kilns for example, and compost which can be used as a fertilizer substitute. Thermal treatment facilities, the so called waste-to-energy, produce electricity and heat. Therefore, solid waste management facilities have to be credited for all those useful "products".

- There is a great deal of uncertainty in a lot of the major solid waste treatment processes. The lack of quality data with respect to waste management practices is a recognized problem of LCA (McDougall, 2001). Landfilling, the most widely used MSW management option, has a lot of uncertainties related to the time frame of the impacts. Obersteiner et al. (2007) report that data relating to processes with direct measurements (such as collection, recycling and treatment) are more reliable than data from landfills which partially have to be modelled and where estimations are necessary.

\section{The life cycle of MSW}

The life cycle of MSW is depicted in Figure 1 by the dotted line. The LCA system boundary is the interface between the waste management system and the environment or other product systems. The life cycle starts once a material or product becomes waste, i.e. its owner discards it in the waste collection bins. MSW is collected either via mixed-bags or via separate collection. Each collection method requires its own infrastructure, i.e. dedicated bins and collection vehicles. The transportation stage follows. In the MSW management 
system of developed countries, the mixed bag waste can either go to the landfill, the wasteto-energy facility or to the Mechanical Biological treatment plant (MBT). The sourceseparated waste, if it is a dry stream (paper and cardboard, plastics, glass, tin, aluminium, etc.), can go to the material reclamation facility or if it is a wet stream (kitchen leftovers, garden trimmings, etc.) can go directly to the biological treatment facility.

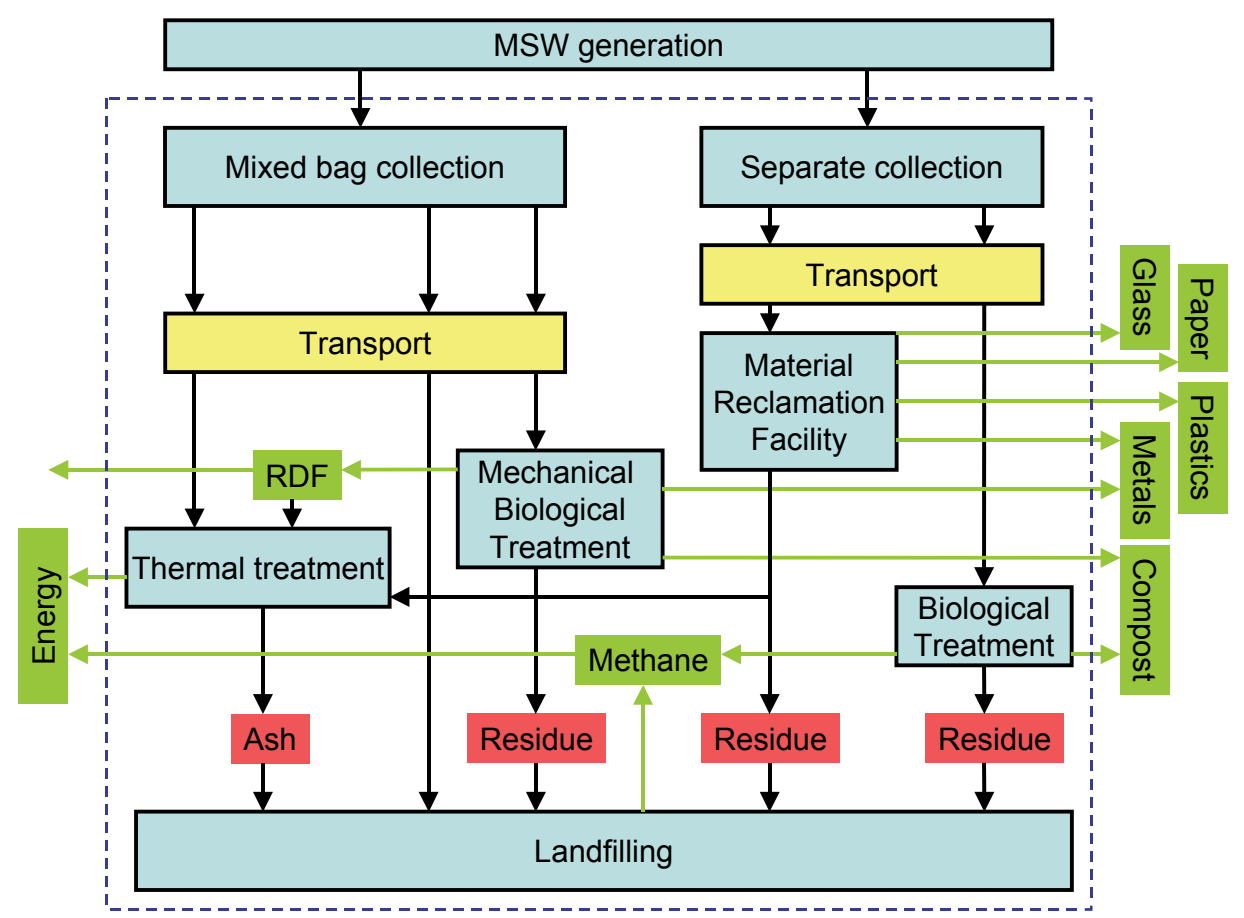

Fig. 1. The complete life cycle of MSW

In every management stage, products are presented in green boxes while residues from each management stage end up in the landfill. The end of the life cycle of MSW is when it ceases to be waste by becoming a useful product, residual landfill material or an emission to either air or water (McDougall, 2001). Landfill, therefore, is an end of the MSW life cycle. The production of useful products resulting from material or energy recovery is also an end of the life cycle of MSW. Figure 1 presents all possible routes for MSW management. This does not imply that each waste stream undergoes every management and treatment step. Please also note that Fig. 1 does not present the resources consumed and the emissions in each management step.

In the following paragraphs, each one of the aforementioned management stages is discussed and the necessary data for the implementation of their life cycle inventory are presented.

\section{The life cycle inventory of MSW management}

LCA assesses the use of resources and the release of emissions to air, water, land and the generation of useful products. All these inputs (material and energy resources) and outputs 
(emissions and products) have to be identified and quantified during the life cycle inventory (LCI) phase of the LCA. In the following sections, the most important LCI components of each management stage are identified and presented. Inputs from natural resources and output emissions are identified in red colour while the useful products in green. The functional unit (FU) is the reference to which the inputs and outputs are related (ISO 14040, 2006).

\subsection{Collection and transport}

Collection of MSW can either be in mixed bags or in separate bins. Mixed bag collection is the most widely applied method; however separate collection is a prerequisite for successful material recovery. Fig. 2 presents the inputs and outputs to the collection and transport stages of MSW management. The inputs are MSW and the materials and energy for the required infrastructure (MSW temporary storage containers and vehicles needed for collection and transportation). The outputs of these processes are again MSW (with altered physical properties such as density) and air, water and solid emissions.

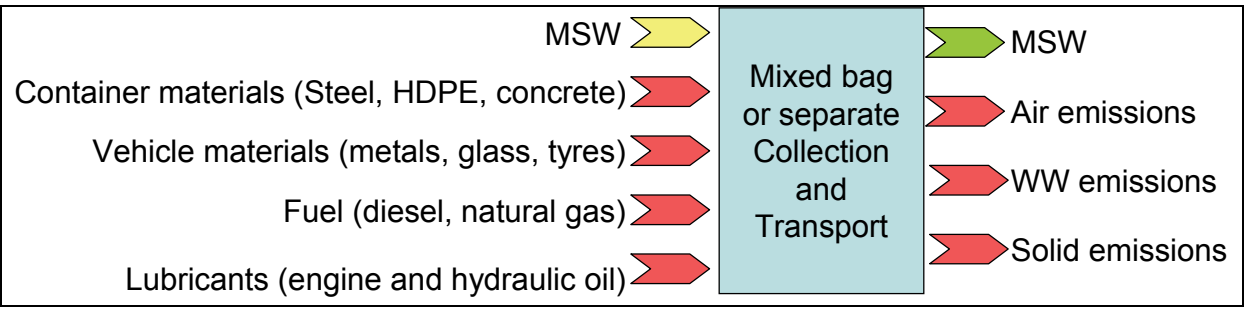

Fig. 2. Life cycle inventory components for the collection and transportation stages.

The following parameters must be taken into account for the compilation of an effective LCI in the collection and transportation stages of an LCA:

- Selective collection system,

- Material of containers (HDPE, steel and fiber glass),

- Collection frequency,

- Distance covered,

- Type of collection truck (pneumatic, top loader, rear loader, side loader),

- Fuel of collection truck (diesel, natural gas),

- Density of the waste fractions in containers and collection trucks,

- Size of containers,

- Filling percentage of the waste containers.

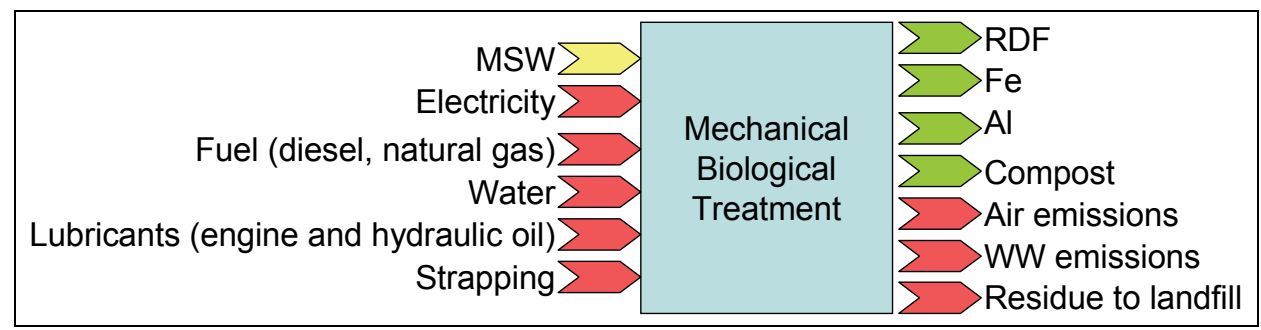

Fig. 3. Life cycle inventory components for the MBT plant. 


\subsection{Mechanical and biological treatment}

Mechanical and biological treatment is a process that generates many useful "products" (see Fig. 3). Its inputs include mixed-bag MSW, electricity, fuels (e.g. diesel and natural gas), water and materials for the required infrastructure (e.g. lubricants and strapping). The outputs are recovered metals ( $\mathrm{Fe}$ and $\mathrm{Al}$ ), RDF (which ultimately can be used as an energy source), compost (which can substitute chemical fertilisers), emissions to air and water and finally a fraction of residue that ends up in the landfill.

\subsection{Thermal treatment}

The major inputs and outputs considered when compiling the LCI of an incineration plant are the following (see Fig. 4): MSW, electricity, other fuels (diesel, natural gas or even coal), water and activated carbon (for air pollution control), are the major inputs. On the other hand, the outputs are: flue gas $\left(\mathrm{HCl}, \mathrm{SO}_{2}, \mathrm{NO}_{x}\right.$, dioxins, $\left.\mathrm{CO}, \mathrm{PM} 10, \mathrm{HF}\right)$, bottom ash, iron scrap, electricity generated, water discharge and air pollution control residues.

\begin{tabular}{|c|c|c|}
\hline $\begin{array}{r}\text { MSW and/or RDF } \sum \\
\text { Fuel (diesel, natural gas) } \sum \\
\text { Electricity } \sum \\
\text { Activated carbon } \sum \\
\text { Lime }\left[\mathrm{Ca}(\mathrm{OH})_{2}, \mathrm{CaO}\right] \sum\end{array}$ & Incineration & $\begin{array}{ll}\sum & \text { Electricity } \\
\sum & \text { Heat } \\
\sum & \text { Water } \\
\sum & \text { Bottom ash } \\
\sum & \text { Exhaust gases } \\
\sum & \text { Fly ash }\end{array}$ \\
\hline
\end{tabular}

Fig. 4. Life cycle inventory components for an incineration plant.

The key factors in modelling incineration in LCA terms are (Chen \& Christensen, 2010): incineration technology (e.g. grated firing, fluidized bed), the heating value of MSW (specified by the MSW composition), the use of auxiliary fuel (type and amount) and leachate disposal methods (e.g. spraying, wastewater treatment).

\subsection{Biological treatment}

Fig. 5 presents the major inputs and outputs for the life cycle inventory of MSW biological treatment. There are two processes included under the term "biological treatment" in MSW management: composting and anaerobic digestion. The biodegradable fraction of the MSW is involved in both of the aforementioned processes. Composting is an aerobic process. The degradable organic carbon in the MSW is converted into $\mathrm{CO}_{2}$.

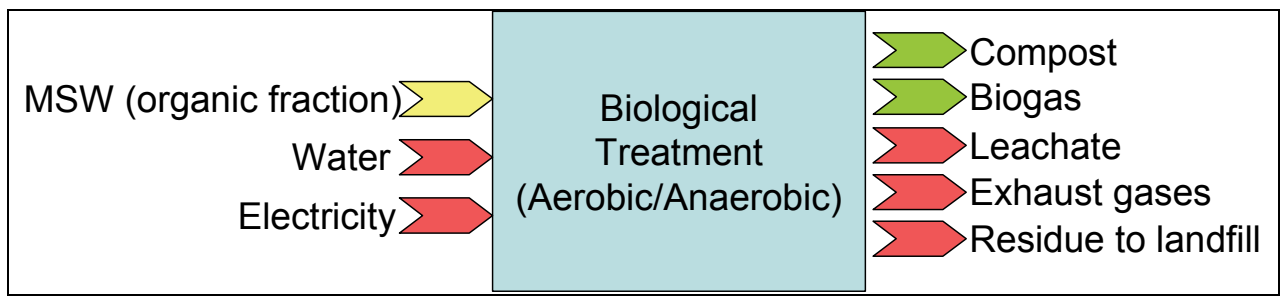

Fig. 5. Life cycle inventory components for biological treatment. 


\subsection{Landfilling}

Landfilling is the first and oldest MSW treatment option. The types of landfilling facilities, all over the world, range from uncontrolled dumpsites to highly engineered facilities with leachate and lanfill gas (LFG) management. Fig. 6 presents the major inputs and outputs for the life cycle inventory of landfilling. When MSW is landfilled directly, anaerobic biological degradation produces landfill gas and leachate. Over $90 \%$ of the converted organic carbon is released as $\mathrm{CO}_{2}$ and $\mathrm{CH}_{4}$. The remainder is released in the leachate (Obersteiner et al., 2007).

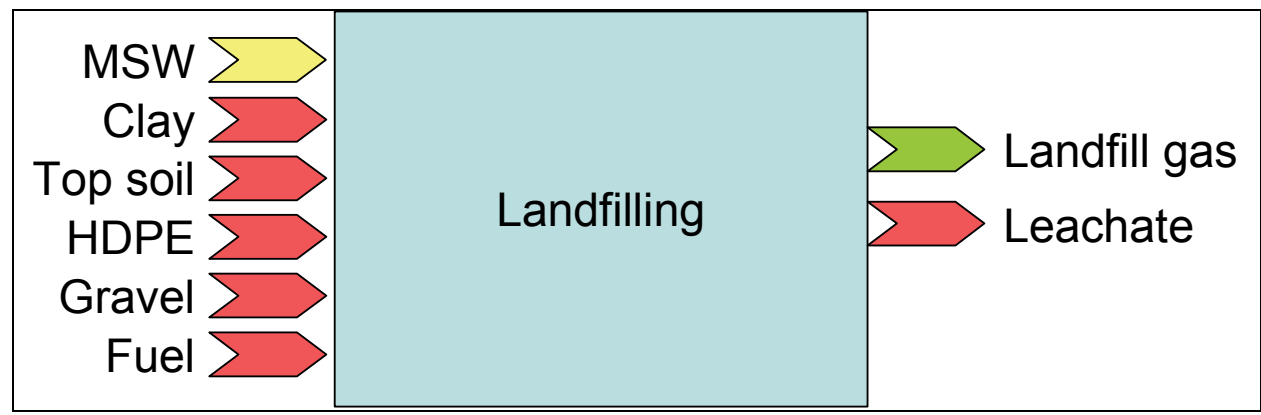

Fig. 6. Life cycle inventory components for landfilling.

Environmental impacts arising from landfills are: leachate (heavy metals and organic loading), emissions into the air $\left(\mathrm{CH}_{4}\right.$, other hydrocarbons), the energy inputs (fuel and electricity) and material inputs for the construction of the engineered landfills (HDPE, clay, gravel, top soil).

\subsection{The contribution of capital equipment and infrastructure}

Waste management systems require capital equipment and infrastructure for their operation, in addition to inputs of energy and materials. All of these equipment and infrastructure consume natural resources and release emissions to the environment during their respective life cycles. These emissions, also known as secondary environmental burdens, tend to be excluded from LCAs of MSW since they are assumed to be relatively small in comparison to primary burdens (McDougall et al., 2001).

\section{Review of selected peer reviewed publications}

All of the reviewed studies appeared recently in peer-reviewed journals. They are presented in chronological order starting from the oldest. They are comparative LCAs that evaluate the consumption of natural resources, environmental emissions and/or performance of various types of MSW management systems. The MSW management stages considered in the reviewed publications are the following:

- Collection and transport,

- Material recovery via separate collection, material recovery facilities or the application of MBT technology,

- Thermal (mostly incineration) and biological treatment (both composting and anaerobic digestion) treatment,

- $\quad$ Final disposal via landfilling. 
Mendes et al. (2003) examine the management of the biodegradable MSW fraction in Sao Paulo, Brazil.

Goal and scope: The goal of the study was to compare composting, biogasification and landfilling. The scope included the analysis of 5 scenarios: i) landfilling, ii) landfilling with energy recovery, iii) composting, iv) composting followed by gas treatment (compost with biofilter) and v) biogasification.

Functional unit: the treatment and disposal of 1 ton of MSW

LCI: the main sources of data were published Japanese LCA reports

Software used: None

Assumptions: Emissions from the construction of facilities were not included in the study because they are assumed to be small compared to those released during the operational stage of the facilities.

LCIA: based on 3 impact categories: global warming potential, acidification potential and nutrient enrichment potential.

Main conclusions: Landfilling was the scenario with the highest environmental impacts, except in the case of acidification potential, in which composting presented the highest potential. Composting without gas treatment presented higher environmental impacts than biogasification. Finally, both composting and biogasification can decrease significantly the impacts compared to landfilling. The authors also mention that both waste composition and carbon intensity of energy sources are very important factors to the outcome of the environmental impact of an MSW management system.

Beigl \& Salhofer (2004) compare different waste management systems of rural communities in the region of Salzburg in Austria.

Goal and scope: The goal of the study was to compare the ecological effects and costs of different waste management systems in a selected rural area in Austria. The scope of the study included 3 scenarios: scenario 1 included recycling by collection in the bring system; scenario 2 included recycling by kerbside collection; scenario 3 was non-recycling.

Functional unit: the amount of communal waste generated annually

LCI: data from the actual practices of collection and treatment were used.

Software used: IWM

Assumptions: Switzerland in 1997 was chosen as the area and year of reference for comparison purposes due to the lack of Austrian data

LCIA: The impact categories examined were the global warming potential, the acidification potential and the net energy use. However, no life cycle impact assessment phase was included, therefore the study is not really an LCA.

Main conclusions: Kerbside collection is ecologically better than collection in the bring system because the specific fuel consumption is lower for collection transports than that for individual transports. With regard to acidification and net energy use, the recycling of metals plays an important role.

Hischier et al. (2005) study the application of LCA on the management of a certain fraction of MSW, namely the waste of electrical and electronic equipment (WEEE).

Goal and scope: The examination in environmental terms of the two Swiss take-back and recycling systems of SWICO (for computers, consumer electronics and telecommunication equipment) and S.EN.S (household appliances). 
Functional unit: All activities linked with the disposal and recycling of WEEE accumulated over one year (2004) in Switzerland.

LCI: Data are derived from the two separate WEEE recycling systems that operate in Switzerland: the SWICO Recycling Guarantee and the S.EN.S system. Each of these systems covers different parts of WEEE. The two systems are well established in Switzerland; In 2004 the systems yielded the recycling of $11 \mathrm{~kg}$ of WEEE per inhabitant, a figure well over the goal of $4 \mathrm{~kg}$ of WEEE recycled defined in the European WEEE directive.

Software used: None

LCIA: Based on the impact categories from the CML methodology were used.

Main conclusions: The take-back and recycling system for WEEE as established in Switzerland has clear environmental advantages, compared to the complete incineration of all WEEE.

Hong et al. (2006) apply LCA to study MBT application in China.

Goal and scope: Comparison of the environmental impact potential of five different alternative waste treatment strategies: i) landfill, ii) incineration, iii) Biological and mechanical treatment (BMT)-compost, iv) BMT-incineration and v) BMT-landfill. In scenario 3 , MSW is firstly pre-treated by BMT and then be composted.

Functional unit: Treatment of 2200 t/day of MSW in the Pudong New Area, in Shanghai, China.

LCI: The primary data come from the incineration plant, the biological compost plant, the landfill yard and Pudong Environmental Protection Bureau.

Software used: none

LCIA: Based on three impact categories: global warming potential (GWP), acidification potential (AP) and eutrophication potential (EP).

Main conclusions: The results of LCA show that the incineration process of MSW presents the highest acidification potential while the landfill presents both the highest global warming and eutrophication potential.

Özeler et al. (2006) study various MSW management methods for Ankara, Turkey.

Goal and scope: The goal of the study was the comparison among five scenarios that included different municipal solid waste processing and/or disposal methods. The management system components considered in the scenarios were: collection and transportation of MSWs, source reduction, material recovery facility/transfer stations, incineration, anaerobic digestion, and landfilling.

Functional unit: The amount of municipal solid waste generated in the districts of Ankara.

LCI: The data collection and preparation were mainly based on information provided by the Solid Waste Management System of Ankara.

Software used: IWM-1

LCIA: The IWM-1 model is an LCI model; therefore there is no explicit LCIA phase

Main conclusions: The scenario which included source reduction, collection, transport and landfilling was the one with minimum contribution in all the impact categories but global warming and FSW, due to the source reduction process and subsequent recycling of the sorted materials in addition to less solid waste input to landfill.

Wanichpongpan \& Gheewala (2007) examine the landfill gas-to-energy conversion in Thailand. 
Goal and scope: The goal of the study was to evaluate the reduction potential of methane gas emissions from MSW landfill. The scope of the study included two scenarios: Scenario 1 included a single landfill using the methane emitted for electricity production. Scenario 2 included two small landfills without electricity production and with flaring of the collected methane

Functional unit: 1 ton of collected MSW

LCI: data from municipalities were collected for the MSW collection and transportation. The Landfill Gas Emissions Model (LandGEM) was used for the quantification of air emissions from landfills. The UNFCCC guidelines were also used.

Software used: None

Assumptions: Leachate treatment is not included as it is common to both scenarios. Emissions from the construction of facilities are also not included since they are assumed small compared to those of the operating facilities.

LCIA: the only impact category of interest to the authors was the global warming potential.

Main conclusions: centralized landfills are viable with landfill gas-to-energy projects and preferable over the current management system of small landfills.

Chaya \& Gweewala (2007) examine the MSW-to-energy schemes in Thailand.

Goal and scope: The goal was to compare the performance of two MSW-to energy schemes, incineration and anaerobic digestion, in terms of environmental impacts and energy balance.

Functional unit: 1 ton of MSW managed

LCI: data for incineration were obtained from a plant in Phuket in South Thailand. For anaerobic digestion, data were obtained from technical manuals and refereed literature.

Software used: SimaPro 5

Assumptions: transportation, construction and maintenance of the plants, and recycling were not included in the study.

LCIA: Based on the Ecoindicator 95 ready-made method

Main conclusions: MSW anaerobic digestion was preferable to incineration. This was partly because more than $60 \%$ of the waste is biodegradable and thus suitable for anaerobic digestion.

Buttol et al. (2007) examine the MSW management system of the Bologna district in Italy.

Goal and scope: The scope of the study was to compare different MSW management options in the Bologna district. The scope of the study included 3 different scenarios: scenario 1 is based on the current MSW practices; scenario 2 anticipates a strong increase in the fraction sent to incineration with energy recovery, the percentage increasing from $30 \%$ to $50 \%$ of the total MSW; scenario 3 anticipates a fraction sent to incineration equal to $37 \%$ of the total waste and a separated collection equal to $31 \%$.

Functional unit: The collection and treatment of 566,000 tons of MSW, which correspond to the annual generation in the district of Bologna for 2006

LCI: Data were obtained from the actual MSW management operations in Bologna Software used: WISARD

Assumptions: Are made on every management step, i.e. incineration with energy recovery, landfilling with energy recovery, composting, sorting and recycling.

LCIA: Based on the following impact categories: greenhouse effect, air acidification, eutrophication, depletion of non-renewable resources, ecotoxicity (sediment, terrestrial, aquatic), human toxicity. 
Main conclusions: There is a clear environmental benefit in increasing recycling and incineration with energy recovery.

Liamsanguan \& Gheewala (2008) examined two methods of MSW for the island of Phuket, Thailand.

Goal and scope: the goal of the study was the comparison of 2 waste management methods used currently for MSW management in the island of Phuket, namely landfilling (without energy recovery), and incineration (with energy recovery). The scope of the study was the comparison in terms of energy consumption and greenhouse gas emissions.

Functional unit: 1 ton of MSW treated

LCI: Information about energy consumption of the MSW management systems was collected from the actual processes at the study site. Emission factors used were based on refereed literature and commercially available databases (BUWAL 300, ETH-ESU).

Software used: None

Assumptions: The treatment of landfill leachate was not included in the study because its energy and resource requirements are negligible. Transportation of MSW was also not included in the study because it is common to both MSW management systems.

LCIA: this study is based just on the life cycle inventory, therefore it is not really an LCA

Main conclusions: Incineration was found to be superior to the landfilling. However, landfilling reversed to be superior when landfill gas is recovered for electricity production.

Iriarte et al. (2009) applied LCA to compare systems or subsystems of waste management and treatment and to identify which areas require an improvement in terms of environmental performance.

Goal and scope: The main objective of the study was to compare the overall environmental impacts of three selective collection services of MSW in dense urban area: i) mobile pneumatic, ii) multi-container, and iii) door to door systems.

Functional unit: The provision of the selective collection service of 1500 tons a month of MSW generated in an urban locality with a density of 5000 inhabitants $/ \mathrm{km}^{2}$, in a European setting, considering a rate of theoretical recovery of $100 \%$ for the following fractions: organic, paper, packaging and glass by means of the aforementioned three selective collection systems.

LCI: The data of the operations and infrastructure of the selective collection systems have been obtained from the field work of the members of the group, management reports and waste management programmes, container companies, waste collection truck suppliers and suppliers of pneumatic waste collection systems.

Assumptions: The main assumptions of the study refer to the fraction densities, the equipment and infrastructure, consumption of resources in waste transport and differences in the values of impact categories.

Software used: SimaPro 7.0.2

LCIA: Based on the CML 2 baseline 2000 method.

Main conclusions: The collection system with the least impact is multi-container collection. The mobile pneumatic system has the greatest environmental impact in the categories of global warming, fresh water aquatic ecotoxicity, terrestrial ecotoxicity, acidification and eutrophication. The door-to-door system has a greater environmental impact in the categories of abiotic depletion, ozone layer depletion and human toxicity. In addition, the door-to-door system has the highest energy demand. This result is mainly due mainly to the 
waste urban transport associated to its longer collection routes. However, the authors claim that the low environmental performance of the door-to-door collection system should be seen in a wider context, since it delivers higher recovery rates of waste compared to the other collection options.

Cherubini et al. (2009) compare selected waste disposal alternatives in a life cycle perspective, considering both landfill systems, where no recycling takes place, and systems which are able to minimize the amount of landfilled waste while maximizing material and energy recovery.

Goal and scope: The goal of this study is to provide a transparent and comprehensive environmental evaluation of a range of waste management strategies for dealing with mixed waste fractions in the city of Roma, Italy. Regarding the scope of the assessment, four different waste management strategies are investigated: Scenario 0: wastes are delivered to landfill without any further treatment; Scenario 1: part of the biogas naturally released by the landfill is collected, treated and burnt to produce electricity; Scenario 2: a sorting plant is present at landfill site for separation of the organic and inorganic fractions and for ferrous metal recovery. Electricity, biogas and compost are then produced on site; Scenario 3: wastes are directly incinerated to produce electricity.

Functional unit: The amount of waste produced in a year (2003) by the city of Roma, which must be disposed of: 1460 kton of wastes contained in the so-called "black sacks" (i.e. presorted and recycled wastes not included).

LCI: Data were compiled from selected references.

Software used: SimaPro 7.1

LCIA: based on global warming potential, acidification potential and eutrophication potential.

Main conclusions: Results show landfill systems (scenarios 0 and 1) are the worst waste management options and that significant environmental savings are achieved from undertaking energy recycling.

De Feo \& Malvano (2009) study various MSW management scenarios in Southern Italy.

Goal and scope: The aim of this study was to apply the LCA procedure to MSW management on the Province of Avellino in Italy in order to choose the "best" management system in environmental terms. The MSW management scenarios considered can be divided into two categories: the first includes scenarios that are based on the incineration of the dry residue, while the second does not consider the thermal treatment of dry residue.

Functional unit:

LCI: All the data necessary for the construction of the analysed scenarios were deduced from the Province of Avellino and the two MSW management companies.

Software used: WISARD

Assumptions: The facility for the production of the RDF was simulated as an MBT plant.

LCIA: The 11 impact assessment categories applied are: renewable energy use, nonrenewable energy use, total energy use, water, suspended solids and oxydable matters index, mineral and quarried, greenhouse gases, acidification, eutrophication, hazardous waste, non hazardous waste.

Main conclusions: The selection of the best scenario depends on the impact category examined. More specifically the scenario that includes $80 \%$ separate collection, no RDF incineration and dry residue sorting was the most preferable for the following six impact 
categories: renewable energy use, total energy use, water, suspended solids and oxydable matters index, eutrophication and hazardous waste. On the other hand, the scenario with $80 \%$ separate collection and RDF production and incineration is preferable for the following three impact categories: non-renewable energy use, greenhouse gases and acidification. Finally, the scenario with $35 \%$ separate collection, RDF production and incineration is the most preferable for the mineral and quarried matters and non-hazardous waste impact categories.

Banar et al. (2009) study various MSW management methods for Eskisehir, Turkey.

Goal and scope: The goal of the study was to analyse and evaluate different alternatives that can be implemented to enable the targets required by the European Landfill and packaging and Packaging Waste Directives for solid waste management in the city of Eskisehir, Turkey. The scope of the study included the development of five alternative scenarios to the current MSW management system, which is uncontrolled dumping. Scenario 1 is an improved version of the current system assuming a 92.7\% landfilling; Scenario 2: A source separation system with efficiency $50 \%$ was added as an improvement to scenario 1 . The recyclables obtained from source separation were sent to the MRF; Scenario 3: The flow of recyclables is similar to scenario 2, while the organic fraction from the MRF is transported to the composting facility. Scenario 4: An incineration process was added instead of a composting facility. All organic wastes and the wastes from the separated recyclables are transported to the incinerator (85\%); Scenario 5: all MSW is sent to the incineration facility $(100 \%)$.

Functional unit: The management of 1 ton of MSW of Eskisehir.

LCI: Data were gathered from actual applications in Eskisehir, literature and the database of SimaPro 7.

Software used: SimaPro 7

LCIA: Based on 6 impact categories included by the CML method, namely: abiotic depletion, global warming, human toxicity, acidification, eutrophication, and photochemical oxidation.

Main conclusions: Recycling of materials leads to lower abiotic depletion. Also, the scenarios that include recycling (S2, S3 and S4) are better than the others in terms of human toxicity (mainly due to the recycling of aluminium). Scenario 3 is the best option in terms of global warming, acidification (because of the displacement of fertiliser), eutrophication and photochemical ozone depletion.

Khoo (2009) compares various waste conversion technologies in Singapore.

Goal and scope: The goal of the study is to compare various waste conversion technologies in Singapore. The scope of the study includes a total of eight waste treatment options for converting an assortment of waste types, including MSW, scrap wood and tyres, organic wastes and RDF into synthetic gas or product gas. All of the technologies are based on pyrolysis and gasification.

Functional unit: 1 ton of product gas produced from the assortment of waste materials

LCI: Data for the 8 technologies are compiled from various reports

Software used: None

LCIA: based on the EDIP 2003 methodology, the following impact categories are reported: global warming potential, acidification potential, terrestrial eutrophication and ozone photochemical formation. 
Main conclusions: Pyrolysis-gasification of MSW and the steam gasification of wood are the most favourable candidates in terms of environmental performance.

Wittmaier et al. (2009) apply LCA in waste utilization systems in an unnamed region in Northern Germany

Goal and scope: The goal of the study was the assessment of the thermal treatment of waste in respect to climate change for various waste treatment systems. The scope included 2 scenarios. Scenario 1 was a conventional thermal treatment, i.e. a waste incineration plant with strokerfired furnace and multistage flue gas cleaning. Scenario 2 was termed as optimized energy recovery and included the specific preliminary separation of the waste materials through mechanical treatment, followed by a subsequent conventional thermal treatment of the separated lower calorific waste fraction as described in Scenario 1. In both scenarios, the landfilling of combustion residues was defined as a further element of the system.

Functional unit: The treatment of 198,000 tonnes of MSW which correspond to the annual amount generated in the district

LCI: Data were compiled from literature and actual operations in Germany

Software used: GaBi 4

LCIA: The only impact category studied was the global warming potential

Main conclusions: The analyses presented in this study show that the thermal treatment of waste in a waste incineration plant can reduce emissions of greenhouse gases compared with depositing the same amount in a landfill, by half. Moreover, a further reduction of the greenhouse gases emissions can be achieved by the energetic utilization of waste with increased calorific value, which could not otherwise be advantageously used in a waste incineration plant.

Rives et al. (2010) compare container systems in MSW. The authors state that the selection of a particular type of waste container by an institution corresponds, in the majority of the cases, to economic or aesthetic criteria, but never to environmental ones. Therefore, the aim of their study is to analyse the potential environmental impact of fourteen MSW container systems, using LCA. The difference among the systems lies in the individual characteristics of the containers, especially the volume and weight of the manufactured materials.

Goal and scope: The objective as to compare and quantify the environmental impact of different MSW waste collection containers, based on their volume and manufacturing material.

Functional unit: The storage of collected and unsorted municipal solid waste (MSW) during the day, in an average neighbourhood of 1000 inhabitants, with a Spanish average waste generation of $1.47 \mathrm{~kg} /$ inhabitant/day and a density of waste container of $106 \mathrm{~kg} / \mathrm{m}^{3}$.

LCI: Nine HDPE and five steel containers were studied, ranging in volumes of 601 to 24001. Assumptions: MSW containers were completely full, containing identical composition of MSW, ii) unsorted waste collection was carried out on a daily basis, and iii) all waste generated was collected unsorted.

Software used: SimaPro 7.1

LCIA: Based on the CML 2 baseline 2000 method. The impact categories considered are: Abiotic depletion potential (ADP), Global warming potential (GWP), Ozone layer depletion potential (OLDP), Acidification potential (AP), Eutrophication potential (EP), Photochemical oxidation potential (POP), Human toxicity potential (HTP), Terrestrial ecotoxicity potential (TEP) 
Main conclusions: A steady reduction in materials was observed as the volume of the waste container increases, for both the HDPE and steel containers. More specifically, the analysis showed that in order to satisfy the functional unit, the smaller volume HDPE container systems (60 1 and 801 ) had the greatest environmental impact. This was true for the majority of the impact categories, except for the EP and HTP categories in which the 6601 and 7701 steel containers had the greatest impact.

A comparison of MSW containers of the same volume and different materials was carried out too. It was observed that HDPE container systems have 1.5-9 times greater environmental impact than the steel containers in most of the category impacts except in the EP, POP and HTP categories. Collection systems that use 24001 steel waste containers have the least environmental impact.

Finally, sensitivity analysis showed that there is a direct dependence among the filling percentage of waste container, the waste collection frequency, the waste generation per capita and the density of the waste container's contents.

Chen \& Christensen (2010) assessed the environmental profile of two MSW incineration technologies that are commonly used in China.

Goal and scope: The goal of the study is the comparison between two incineration technologies with semi-dry flue gas cleaning for treating MSW in southern China, namely grated firing and fluidized bed. The scope of the study included nine different scenarios based on the aforementioned incineration technologies.

Functional unit: 1 ton of waste arrived at the incineration plant

LCI: based on the databases of the software used

Software used: EASEWASTE

LCIA: Based on the EDIP 1997 method. The important impact categories related to incineration are: global warming (100 years), acidification, nutrient enrichment, human toxicity via soil, water and air, ecotoxicity, bulky waste, photochemical ozone formation, slag and ashes.

Main conclusions: for MSW with Lower Heating Value high enough for self-maintained combustion (e.g. as high as $6.05 \mathrm{MJ} / \mathrm{kg}$ ) the fluidized bed incineration without coal consumption saves more potential impacts than grate furnace incineration technology for most of the evaluated impact categories.

Abduli et al. (2010) compare 2 different MSW management scenarios in Tehran, Iran.

Goal and scope: The goal of the study was to compare the environmental impacts of two MSW management practices. The scope was to compare landfill (scenario 1) and composting plus landfill (scenario 2) for the management of MSW in the city of Tehran.

Functional unit: 1 ton of MSW

LCI: Data gathered from actual applications in Tehran, literature and the database of LandGem model are used

Software used: None

Assumptions: Landfill has a gas collection system with $50 \%$ collection efficiency

LCIA: Seven impact categories are considered to be representative of the potential environmental impact of MSW management in Tehran: climate change, acidification, respiratory effect, carcinogenesis, ecotoxicity, ozone layer depletion and surplus energy for future extraction. 
Main conclusions: The study shows that scenario 2 (composting plus landfill) has a higher environmental impact compared to landfilling, despite the fact that the fraction of organic waste in MSW is quite high (67.8\%)

Miliūtė \& Staniškis (2010) apply LCA on the MSW management systems in Lithuania.

Goal and scope: The goal of the study was to compare different waste management options for the MSW in the region of Alytus, Lithuania. The scope of the study included 5 different scenarios: Scenario 1 was based on landfilling; scenario 2 included recycling, composting and landfilling; scenario 3 was based on recycling, composting, MBT and incineration; scenario 4 was based on recycling and incineration while scenario 5 included recycling, MBT and incineration.

Functional unit: the MSW generated in one year (2005): 45,150 tonnes

LCI: waste composition data were extracted from empirical studies in the region of Alytus. Data were also extrapolated from official Lithuanian statistics. The data on incineration processes are based on the average Swedish technologies.

Software used: WAMPS

Assumptions: The time boundary of the study was set at 10 years. Assumptions are made for all the waste management options (incineration, landfilling, composting, recycling) of the study.

LCIA: based on 4 impact categories: global warming, acidification, eutrophication and photo-oxidant formation

Main conclusions: Landfilling gives the worst environmental results compared to the other waste management options. Furthermore, when it comes to the biodegradable waste fraction, aerobic composting is not a better option compared to incineration with energy recovery in all impact categories.

Morris (2010) compares waste-to-energy (WTE) and landfill (LF) gas for electricity generation in North America in terms of greenhouse gases (GHG) emissions.

Goal and scope: there are two goals in the study: the first one is to compare WTE and LF in terms of their climate impact; the second one is to compare MSW, natural gas and coal for power production in terms of climate impact.

Functional unit: for the comparison of Waste-to-energy and landfilling the FU is 1 metric ton of MSW shipped from a transfer facility to LF or WTE for disposal; for the comparison of the GHG releases for power production from MSW, natural gas and coal the FU is the amount of fuel required to produce 1 kilowatt hour $(\mathrm{kWh})$

LCI: data are based on three different levels of North American geographic specificity: the city of Seattle, the metropolitan area of Vancouver and the state of Massachusetts.

Software used: None

Assumptions: GHG emissions from construction of capital and operating equipment are not included in either inventory.

LCIA: the only impact category considered is climate change

Main conclusions: The author defines the "crossover rate" as the LFG capture rate at which burning and burying have equal GHG emissions. Above the crossover rate, LF has lower GHG emissions than WTE. Below the crossover rate, WTE is better for the climate. Seattle and Massachusetts crossover rates are higher than Metropolitan Vancouver, mainly due to to Seattle and Massachusetts MSW having lower fossil carbon content, which results in lower WTE fossil $\mathrm{CO}_{2}$ emissions. Regarding the comparison for power generation, natural 
gas is the best option. WTE emissions are lower if LCA system boundaries are expanded to include offsets for recovering scrap metals from WTE bottom ash.

Fruergaard \& Astrup (2011) compare waste-to-energy technologies in Denmark.

Goal and scope: The goal was to compare two different waste-to-energy technologies (cocombustion in coal-fired power plants and anaerobic digestion) with mass burn incineration with and without energy recovery. The scope of the study included two different waste fractions: i) a high calorific fraction (SRF) suitable for co-combustion and ii) organic waste suitable for biological treatment. In total 7 different combinations of WTE technologies and waste fractions were examined.

Functional unit: utilization of 1 tonne of SRF/organic waste for energy purposes, including collection and pre-treatment.

LCI: data were collected from refereed literature and operation of incinerators in Denmark Software used: EASEWASTE

Assumptions: production of capita; goods was not included as their impacts were assumed to be of minor importance per tone of waste throughout the life cycle of the plants

LCIA: Based on the EDIP 1997 method. The impact categories are: global warming, acidification, nutrient enrichment, photochemical ozone formation, human toxicity via soil, water and air, ecotoxicity in water and in soil.

Main conclusions: Overall, waste incineration with efficient energy recovery proved to be a very environmentally competitive solution based on Danish conditions. Co-combustion of SRF at modern power plants appeared fully comparable provided that sufficiently well flue gas cleaning systems are installed. Anaerobic digestion of organic waste materials appeared less preferable overall.

\section{Conclusions}

Based on the 21 references reviewed in the chapter, the following conclusions can be drawn: LCA has been applied to various MSW management stages covering the whole MSW life cycle: 3 publications refer to collection (Rives et al., 2010; Iriarte et al., 2009; Beigl \& Salhofer, 2004); 10 publications refer to integrated MSW management (Abduli et al., 2010; Miliūtè \& Staniškis, 2010; Banar et al., 2009; Cherubini et al., 2009; De Feo \& Malvano, 2009; Khoo, 2009; Liamsanguan \& Gweewala, 2008; Buttol et al., 2007; Hong et al., 2006, Özeler et al., 2006); 6 publications refer to waste-to-energy schemes (Fruergaard \& Astrup, 2011; Chen \& Christensen, 2010; Moris, 2010; Wittmaier et al., 2009; Chaya \& Gweewala, 2007; Wanichpongpan \& Gweewala, 2007); Finally, there are 2 publications that deal with specific MSW streams: 1 for WEEE (Hischier et al., 2005) and 1 for the biodegradable fraction of MSW (Mendez et al., 2003).

Regarding the collection and storage of MSW, LCA revealed the following conclusions: smaller volume containers have the greatest environmental impact (Rives et al., 2010); HDPE containers have greater impact compared to steel (Rives et al., 2010); the multi container collection system has the least environmental impact while the door-to-door system has the greatest (Iriarte et al., 2009); kerbside collection is environmentally better than collection in the bring system (Beigl \& Salhofer, 2004).

Coming now to the integrated MSW management, the following conclusions were identified: landfills are the worst management options (Miliūtė \& Staniškis, 2010; Cherubini et al., 2009; Wanichpongpan \& Gweewala, 2007; Hong et al., 2006; Mendes et al., 2003); 
significant environmental savings are achieved from energy recovery (Fruergaard \& Astrup, 2011; Cherubini et al., 2009; Khoo, 2009; Wittmaier et al., 2009; Liamsanguan \& Gweewala, 2008; Buttol et al., 2007; Wanichpongpan \& Gweewala, 2007); the same is true for material recovery, especially metals (Morris, 2010; Banar et al., 2009; Buttol et al., 2007; Özeler et al., 2006; Hischier et al., 2005); the selection of the best scenario depends on the impact category examined (De Feo \& Malvano, 2009).

Finally, the waste-to-energy case studies, in addition to the aforementioned conclusions, reveal the following: energetic utilisation of waste with increased calorific value should be pursued (Wittmaier et al., 2009); the fluidized bed incineration without coal consumption saves more potential impacts than grate furnace incineration technology (Chen \& Christensen, 2010); electricity from waste-to-energy incineration is not better than electricity from natural gas (Morris, 2010); waste incineration is preferable to anaerobic digestion for Fruergaard \& Astrup (2011); however, the opposite is reported by Chaya \& Geweewala (2007).

\section{References}

Abduli M .A., Naghib A., Yonesi M., \& Akbari A. (2010). Life cycle assessment (LCA) of solid waste management strategies in Tehran: landfill and composting plus landfill. Environ. Monit. Assess., DOI: 10.1007/s10661-010-1707-x

Banar, M., Cokaygil, Z., \& Ozkan, A. (2009) Life cycle assessment of solid waste management options for Eskisehir, Turkey. Waste Management, 29, 54-62

Beigl P. \& S. Salhofer (2004). Comparison of ecological effects and costs of communal waste management systems. Resources, Conservation and Recycling, 41, 83-102.

Buttol, P., Masoni, P., Bonoli, A., Goldoni, S., Belladonna, V., \& Cavazzuti, C. (2007) LCA of integrated MSW management systems: Case study of the Bologna District. Waste Management, 27, 1059-1070

Chaya, W., \& Gheewala, S.H. (2007) Life cycle assessment of MSW-to-energy schemes in Thailand. Journal of Cleaner Production, 15, 1463-1468

Chen D \& T.H. Christensen (2010). Life-cycle assessment (EASEWASTE) of two municipal solid waste incineration technologies in China. Waste Management $\mathcal{E}$ Research, 28(6), 508-519

Cherubini, F., Bargigli, S., \& Ulgiati, S. (2009) Life cycle assessment (LCA) of waste management strategies: Landfilling, sorting plant and incineration. Energy, 34, 2116-2123

De Feo, G., \& Malvano, C. (2009) The use of LCA in selecting the best management system. Waste Management, 29, 1901-1915

Finlay, P.N., (1989). Introducing Decision Support Systems, Blackwell, Oxford, UK.

Fruergaard T., \& T. Astrup (2011). Optimal utilization of waste-to-energy in an LCA perspective. Waste Management, 31, 572-582

Güereca, L.P., Gassó, S., Baldasano, J.M., \& Jiménez-Guerrero, P. (2006) Life cycle assessment of two biowaste management systems for Barcelona, Spain. Resources, Conservation and Recycling, 49, 32-48

Hischier, R., Wäger, P., \& Gauglhofer, J. (2005) Does WEEE recycling make sense from an environmental perspective? The environmental impacts of the Swiss take-back and recycling systems for waste electrical and electronic equipment (WEEE). Environmental Impact Assessment Review, 25, 525-539 
Hong, R.J., Wang, G.F., Guo, R.Z., Cheng X., Liu Q., Zhang P.J. \& Qian G.R. (2006). Life cycle assessment of BMT-based integrated municipal solid waste management: Case study in Pudong, China. Resources, Conservation and Recycling, 49, 129-146

Iriarte, A., Gabarell, X., \& Rieradevall, J. (2009) LCA of selective waste collection systems in dense urban areas. Waste Management, 29, 903-914

ISO 14040 (2006) Environmental management-life cycle assessment-requirements and guidelines. International Organisation for Standardisation (ISO), Geneva

Khoo, H. H. (2009) Life cycle impact assessment of various conversion technologies. Waste Management, 29, 1892-1900

Koneczny K., Pennington, D.W. (2007). Life cycle thinking in waste management: Summary of European Commission's Malta 2005 workshop and pilot studies. Waste Management, 27, S92-S97

Liamsanguan, C., \& Gheewala, S.H. (2008) LCA: A decision support tool for environmental assessment of MSW management systems. Journal of Environmental Management, 87, 132-138

McDougall F.R., White P., Franke M., \& Hindle P. (2001). Integrated Waste Management: A Life Cycle Inventory (2nd ed.). Blackwell Science, Oxford UK

McDougall, F.R. (2003). Life Cycle Inventory Tools: Supporting the Development of Sustainable Solid Waste Management Systems. Corporate Environmental Strategy, $8(2), 142-147$

Mendes, M.R., Aramaki, T., \& Hanaki, K. (2004) Comparison of the environmental impact of incineration and landfilling in Sao Paulo city as determined by LCA. Resources, Conservation and Recycling, 41, 47-63

Miliūtè J., \& Staniškis, J. K. 2010. Application of life-cycle assessment in optimisation of municipal waste management systems: the case of Lithuania. Waste Management $\mathcal{E}$ Research, 28, 298-308

Morris J. (2010). Bury or Burn North America MSW? LCAs Provide Answers for Climate Impacts \& Carbon Neutral Power Potential. Environ. Sci. Technol., 44, 7944-7949

Obersteiner G., Binner, E., Mostbauer, P. \& S. Salhofer (2007). Landfill modelling in LCA A contribution based on empirical data. Waste Management, 27, S58-S74

Özeler, D., Yetis, Ü., \& Demirer, G.N. (2006) Life cycle assessment of municipal solid waste management methods: Ankara case study. Environment International, 32, 405-411

Rebitzer, G., Ekvall, T., Frischknecht, R., Hunkeler, D., Norris, G., Rydberg, T., Schmidt, W.T, Suh S., Weidema, B.P., \& Pennington, A.W. (2004) Life cycle assessment - Part 1: Framework, goal and scope definition, inventory analysis, and applications. Environment International, 30, 701-720

Rives, J. Rieradevall, J., \& Gabarell, X. (2010) LCA comparison of container systems in municipal solid waste management. Waste Management, 30, 949-957

Rodríguez-Iglesias, J., Marañón, E., Castrillón, L., Riestra, P, \& Sastre, H. (2003) Life cycle analysis of municipal solid waste management possibilities in Asturias, Spain. Waste Management $\mathcal{E}$ Research, 21, 535-548

Wanichpongpan, W., \& Gheewala, S.H. (2007) Life cycle assessment as a decision support tool for landfill gas-to energy projects. Journal of Cleaner Production, 15, 1819-1826

Winkler, J., \& Bilitewski, B. (2007) Comparative evaluation of life cycle assessment models for solid waste management. Waste Management, 27, 1021-1031

Wittmaier, W., Langer, S., \& Sawilla, B. (2009) Possibilities and limitations of life cycle assessment (LCA) in the development of waste utilization systems - Applied examples for a region in Northern Germany. Waste Management, 29, 1732-1738 


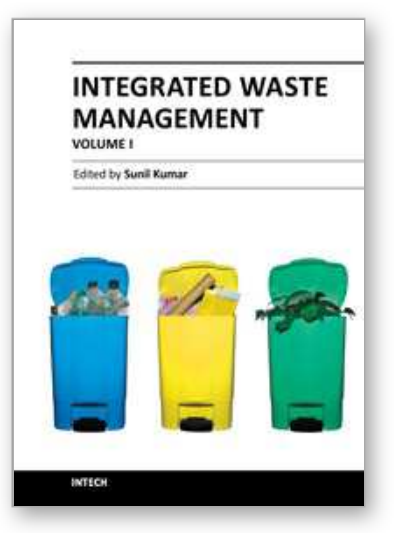

\author{
Integrated Waste Management - Volume I \\ Edited by Mr. Sunil Kumar
}

ISBN 978-953-307-469-6

Hard cover, 538 pages

Publisher InTech

Published online 23, August, 2011

Published in print edition August, 2011

This book reports research on policy and legal issues, anaerobic digestion of solid waste under processing aspects, industrial waste, application of GIS and LCA in waste management, and a couple of research papers relating to leachate and odour management.

\title{
How to reference
}

In order to correctly reference this scholarly work, feel free to copy and paste the following:

Konstadinos Abeliotis (2011). Life Cycle Assessment in Municipal Solid Waste Management, Integrated Waste Management - Volume I, Mr. Sunil Kumar (Ed.), ISBN: 978-953-307-469-6, InTech, Available from:

http://www.intechopen.com/books/integrated-waste-management-volume-i/life-cycle-assessment-in-municipalsolid-waste-management

\section{INTECH}

open science | open minds

\section{InTech Europe}

University Campus STeP Ri

Slavka Krautzeka 83/A

51000 Rijeka, Croatia

Phone: +385 (51) 770447

Fax: +385 (51) 686166

www.intechopen.com

\section{InTech China}

Unit 405, Office Block, Hotel Equatorial Shanghai

No.65, Yan An Road (West), Shanghai, 200040, China

中国上海市延安西路65号上海国际贵都大饭店办公楼 405 单元

Phone: +86-21-62489820

Fax: +86-21-62489821 
(C) 2011 The Author(s). Licensee IntechOpen. This chapter is distributed under the terms of the Creative Commons Attribution-NonCommercialShareAlike-3.0 License, which permits use, distribution and reproduction for non-commercial purposes, provided the original is properly cited and derivative works building on this content are distributed under the same license. 